\title{
A EDUCAÇÃO A DISTÂNCIACOMO OPORTUNIDADE DE FORMAÇÃO PROFISSIONAL E TECNOLÓGICA
}

\author{
(DISTANCE EDUCATION AS AN OPPORTUNITY FOR TECHNOLOGICAL AND PROFESIONAL \\ VOCATIONAL TRAINING)
}

Cinara Ourique do Nascimento

Instituto Federal de Educação, Ciência e Tecnologia Sul-rio-grandense (IFSul), Brasil

Sheyla Costa Rodrigues

Universidade Federal do Rio Grande (FURG), Brasil

\section{RESUMO}

A inquietação em torno da oferta da Educação Profissional e Tecnológica a distância moveu-nos a refletir sobre essa realidade de ensino técnico. Traçamos nossa investigação em torno dos polos de apoio presencial, solicitando às professoras coordenadoras que respondessem algumas questões sobre o programa Rede e-Tec Brasil e os cursos técnicos a distancia ofertados pelo IFSul/CaVG. Através da metodologia do Discurso do Sujeito Coletivo, foi possível conhecer o discurso dessa coletividade propiciando uma interlocução entre as vozes das coordenadoras e as dos teóricos que fundamentaram o estudo. $\mathrm{O}$ discurso coletivo destaca a importância da qualificação profissional para a melhoria de vida e para o desenvolvimento econômico e social dos municípios, bem como, a aceitação da educação a distancia como oportunidade de acesso àqueles que se encontram distanciados dos bancos escolares regulares.

Palavras chave: educação a distância, educação profissional e tecnológica, política pública.

\section{ABSTRACT}

Certain questions surrounding the provision of professional and technological distance education lead us to reflect on the current reality in technical training. This research is placed within the context of two onsite polarities. In the first place, we asked the respective online education coordinators about the Brazilian Red e-Tec program. Second, we looked at the technical courses that are being offered by IFSul/CaVG. By means of the Collective Subject Discourse methodology, it was possible to provide a dialogue between the course coordinators and the theorists, which are used as the foundations of this study. Collective 
discourse highlights the importance of professional qualifications to improve quality of life or the economic /social development of municipalities. Within this rubric, it also considers the acceptance of distance education as an opportunity for students, namely those who are not located near regular schooling facilities.

Keywords: distance education; professional and technological education; public policies.

A Educação Profissional e Tecnológica (EPT), hoje, é vista como promotora da compreensão do trabalho enquanto princípio educativo e cultural, sendo entendida não apenas como uma educação voltada, exclusivamente, para uma formação executora laboral, mas também como uma formação mais integral do trabalhador, orientada para um saber científico, tecnológico e cultural com vistas ao pensamento crítico e a políticas sociais e econômicas de suporte aos arranjos produtivos locais. Nesse sentido, a EPT procura dar conta de uma formação voltada para a ciência e a tecnologia, na confluência de conhecimentos, saberes e competências mais abrangentes e não mecanicistas.

Essa realidade do mundo do trabalho é evidenciada nos avanços propiciados pela tecnologia, acoplados a uma profunda crise mundial que reivindica a substituição de estruturas estáticas por mecanismos dinâmicos de mudanças, conforme lembra Capra (1989), modificando os processos de produção, as relações capitalistas e a comunicação (Castells, 2002). Nessa dinâmica de movimentos, a sociedade vive períodos importantes e intensos de perturbações que passam a modificar e guiar o desenvolvimento da mesma, exercendo influência em nossos valores, padrões de comportamento, hábitos, crenças e, principalmente, permitindo uma nova maneira de entender o mundo.

Para Maturana (2006a) a tecnologia pode ser orientadora do modo de viver dos seres humanos, ampliando as habilidades operacionais em todos os domínios da atividade humana. Essa visão permite não incorrer no erro de interpretação de que as tecnologias são a solução para todos os problemas do mundo. Dessa forma, podemos aceitar o progresso tecnológico sem deixar suplantar nossa existência como se fôssemos aderir a forças sobrenaturais de forma inconsciente. Nesse contexto, é possível a transposição dos tradicionais modelos educacionais às possibilidades oferecidas pela tecnologia. Atualização, adaptação e inovação são elementos que compõem as estratégias educacionais para acompanhar uma sociedade que clama por inclusão.

Na perspectiva da EPT, está o desafio de ofertar cursos técnicos na modalidade a distância (EaD), agora mediados pelas tecnologias de informação e comunicação (TIC's). Para viabilizar a proposta de ensino profissional a distância, foi criado, em 
2007, o Programa Escola Técnica Aberta do Brasil - e-Tec Brasil, que, em termos de política pública educacional, oferece, em regime de colaboração entre a União, Estados, Distrito Federal e Municípios, um maior acesso à formação profissional e tecnológica, ampliando a oferta dos cursos técnicos de nível médio em todo o território nacional.

Em 2011, o programa ampliou seus objetivos e permitiu a adesão de novas unidades de ensino, tornando-se uma das ações do Pronatec ${ }^{1}$. Nesse mesmo ano, por conta da ampliação do seu escopo, o programa passou a chamar-se Rede e-Tec Brasil ${ }^{2}$, regulamentada pelo Decreto 7.589 de 26 de Outubro de 2011. A funcionalidade da rede é garantida pela Secretaria de Educação Técnica e Tecnológica do Ministério da Educação - SETEC/MEC, através de dotações orçamentárias do Ministério da Educação e do Fundo Nacional de Desenvolvimento da Educação - FNDE, para a execução dos cursos.

Diante da nova organização da EPT com a modalidade de EaD, assistimos a um conjunto de situações - estruturais, políticas, sociais e educacionais, - ainda embrionárias vivenciadas no âmbito da Rede e-Tec Brasil, que impõem o desafio de contextualizar, refletir e problematizar essa outra realidade que se apropria do ensino técnico e tecnológico no Brasil.

Desse modo, desejamos dar materialidade a uma escrita que possa trazer reflexões, considerações e a reformulação da experiência com elementos da própria experiência envolvendo a Educação Profissional e Tecnológica a distância no Instituto Federal de Educação, Ciência e Tecnologia Sul-rio-grandense - Campus Pelotas Visconde da Graça (IFSul/CaVG), situado no município de Pelotas/RS/ Brasil, bem como contribuir com conhecimentos no campo das ciências que estudam a Educação Profissional e Tecnológica nesta modalidade.

\section{A EDUCAÇÃo PROFISSIONAL E TECNOLÓgICA E A REDE E-TEC BRASIL}

Organizada e institucionalizada desde 1909, quando foi criada pelo Presidente Nilo Peçanha, a Educação Profissional e Tecnológica passou por diversos momentos históricos, destacando como marco inicial a efetivação das " "dezenove Escolas de Aprendizes Artífices”, destinadas ao ensino profissional, primário e gratuito" (Brasil, 2009, p.2). Acompanhando as mudanças no cenário brasileiro, a Constituição de 1937 transforma as Escolas de Artífices em Liceus Profissionais, objetivando que a oferta do ensino profissional fosse além da simples inclusão dos menos favorecidos, 
mas possibilitando uma formação qualificada que atendesse o desenvolvimento e a expansão da indústria brasileira naquele momento.

Em 1959, acompanhando o "milagre brasileiro", houve profunda transformação da EPT, pois as Escolas Industriais e Técnicas foram transformadas em Escolas Técnicas Federais, intensificando a formação de mão de obra especializada diante da demanda da industrialização. Em 1971, a Lei de Diretrizes e Bases da Educação Brasileira - LDB 5.692 de 11/o8/1971 estabeleceu a obrigatoriedade do ensino técnico-profissional ao currículo de nível médio, sinalizando para a intensificação da formação de técnicos de forma emergencial. Tal fato foi um importante elemento histórico na consolidação da Educação Profissional e Tecnológica no país.

Já em 1994, a lei 8948/94 instituiu o sistema Nacional de Educação Tecnológica, que autorizou a transformação de mais Escolas Técnicas Federais em Centro Federais de Educação Tecnológica - CEFET's. Esta Lei iniciou as mudanças que culminaram na criação da Rede Federal de Educação Profissional e Tecnológica, existente até hoje (Brasil, 2009).

Atualmente, o Parecer da CNE/CEB 11/2012 retrata a concepção da Educação Profissional e Tecnológica como a necessidade de considerar que a ciência e a tecnologia são estruturas pertencentes à história e à cultura da sociedade, tanto no âmbito político como no social. O parecer apresenta ainda uma Educação Profissional e Tecnológica que vai além de uma concepção de política assistencialista ou como simples forma de atender as demandas do mercado, mas passa a ser concebida como uma estratégia de alcance do cidadão à ciência e à tecnologia (Brasil, 2012).

Na caminhada da EPT, talvez a mudança mais significativa no âmbito da Rede Federal de Educação Profissional e Tecnológica tenha ocorrido com a criação dos Institutos Federais de Educação, Ciência e Tecnologia - IF's, pois articulam ensino, ciência e tecnologia "relacionada com as demandas básicas do desenvolvimento nacional, tanto no tocante à formação dos trabalhadores e o fortalecimento de sua cidadania, quanto aos desafios do desenvolvimento da ciência brasileira" (Pacheco, Pereira e Sobrinho, 2010, p.83). Os institutos nascem com o desafio de atuar em todos os níveis e modalidades de ensino, atendendo a uma formação com vistas a uma "educação como instrumento de transformação e de enriquecimento do conhecimento, capaz de modificar a vida social e atribuir maior sentido e alcance ao conjunto da experiência humana" (Silva, 2009, p. 10).

Na continuidade da amplitude da EPT, em 2007, o Ministério da Educação, por intermédio da Secretaria de Educação Profissional e Tecnológica - SETEC e da 
extinta Secretaria de Educação a Distancia - SEED, abriu o Edital 01/2007/SEED/ SETEC/MEC, convocando as Instituições públicas, federais, estaduais e municipais que ministram o ensino técnico de nível médio, a apresentarem propostas para a oferta deste nível através da modalidade a distância, para municípios e Distrito Federal dispostos a receberem esses cursos. Este é o primeiro instrumento que sinaliza a materialização da oferta da Educação Profissional Tecnológica a distância, com vistas à expansão do acesso ao mundo do trabalho por jovens e adultos, à reinserção de trabalhadores e à interiorização do ensino profissional.

De acordo com Pacheco (2010), a Rede e-Tec Brasil caracteriza-se como uma das políticas educacionais implementadas pelo governo em contraposição ao pensamento neoliberal, através da ampliação de vagas públicas que possibilitam o acesso à educação para milhões de jovens e adultos trabalhadores. O programa reafirma-se com a finalidade de desenvolver a educação profissional e tecnológica na modalidade de $\mathrm{EaD}$, compreendida como estratégia de ascensão à escolaridade, tendo como preceito a permanência e continuidade de estudos.

É possível visualizar que a Rede e-Tec Brasil é uma das ações que preconiza a expansão da oferta do ensino técnico. O que nos parece preocupante é o modelo no qual foi concebida, pois suas normas e diretrizes seguem, em alguns momentos, a mesma formatação de gestão e legislação dada ao ensino superior na modalidade de EaD. Entendemos que, apesar de existirem normatizações que estabeleçam orientações sobre o funcionamento da Rede e-Tec Brasil, se faz necessário efetivar uma legislação própria e um desenho organizacional específico capaz de atender as peculiaridades da Educação Profissional e Tecnológica a distancia. No entanto, ainda que esses elementos tragam preocupações acerca da institucionalização da Rede e-Tec Brasil, é vislumbrada uma gama de intenções para seu fortalecimento, enquanto política pública, por transparecer um meio possível para mudança da realidade social em que vivemos.

Para Moore e Kearsley (2008, p.13) o grande o desafio da educação a distância, hoje, está no,

[...] desenvolvimento de políticas, pelos legisladores, que ajudem as organizações educacionais a passarem de uma abordagem artesanal de ensino para uma abordagem sistêmica; os administradores, a redistribuírem os recursos humanos e financeiros sob sua responsabilidade em um sistema total, e os professores, a serem treinados para trabalharem como especialistas em tal sistema. 
Com esse entendimento, o Instituto Federal de Educação, Ciência e Tecnologia - Sul-rio-grandense- Campus Pelotas Visconde da Graça (IFSul/CaVG), passa a ser um integrante da proposta do programa Rede e-Tec Brasil.

\section{A EDUCAÇÃo PROFissional E TECNOLÓgicA A Distancia No IFSUL/CAVG}

O Campus CaVG, como é conhecido atualmente, constituiu-se originariamente pelo Patronato Agrícola em 1921, "criado, objetivando auxiliar o homem do campo através do aprendizado de seu filho [...]" (Antunes, 1996, p. 23). Após esse marco inicial, vários foram os períodos históricos e políticos que promoveram uma reorganização do ensino até que, em 1947, o então Aprendizado Agrícola Visconde da Graça, passou a chamar-se Colégio Agrícola Visconde da Graça - CaVG. O Colégio foi incorporado como unidade da Universidade Federal de Pelotas (UFPEL), do Ministério da Educação e Desporto, pelo Decreto ${ }^{\circ}$ 56.881, de 16 de dezembro de 1969, tornando-se uma Escola Agrotécnica vinculada à UFPEL.

Atualmente, após a criação dos Institutos Federais de Ciência e Tecnologia, mais precisamente no ano de 2010, o CaVG passa a ser chamado de Campus Pelotas Visconde da Graça- CaVG (grifo nosso), sendo um dos Campi vinculado ao Instituto Federal Sul-rio-grandense (IFSul), constituído como um campus de Educação Profissional e Tecnológica, nos níveis médio, técnico, superior e de pós-graduação.

Com um olhar para a história do CaVG, podemos observar que ele traz na sua trajetória educacional o compromisso com uma educação voltada para a formação de profissionais capazes de serem inseridos no mundo do trabalho tanto por sua capacidade técnica como por sua formação de cidadão. Inicialmente, o CaVG restringia-se à oferta de cursos profissionais de nível técnico, voltados para os diversos eixos dos saberes profissionais. Até a década de 90, o perfil dos cursos atendia filhos de pequenos produtores rurais que subsistem em regime de agricultura familiar ou como empregados do agronegócio. Nos anos posteriores, após cerca de meio século como Escola Agrotécnica, o CaVG passa a inovar, incorporando no seu perfil educacional, cursos superiores de tecnologia, Licenciatura, educação a distância e pós-graduação, atendo diversas áreas do conhecimento.

Assim, o CaVG constitui-se em um campus com um perfil politécnico ao diversificar a oferta de vagas nos níveis e modalidades de ensino, ofertando novas oportunidades às comunidades local e regional. 
Esta trajetória profícua na educação direciona o CaVG a refletir sobre uma organização que se (re)configura a partir dos desafios impostos, seja pelas demandas da sociedade; seja pela necessidade de pensar o presente ou repensar-se enquanto provedor da formação de cidadãos. É nessa circularidade que sua cultura se (re) inventa para dar uma continuidade institucional ao ensino técnico e tecnológico, agora de responsabilidade dos Institutos.

Em 2007, através do Programa Rede e-Tec Brasil, o CaVG insere-se na modalidade de educação a distancia, ofertando inicialmente, dois cursos técnicos (Agroindústria e Biocombustíveis) com 450 vagas em 5 municípios do Rio Grande do Sul, que sediam polos de apoio presencial.

Segundo o Parecer CNE/CEB 11/2012, todos os princípios e concepções que orientam a Educação Profissional e Tecnológica são igualmente válidos para a oferta na modalidade de Educação a Distância, ou seja, a oferta de cursos técnicos de nível médio a distância devem ser orientados pelo Catálogo Nacional de Cursos Técnicos determinados pela Secretaria de Educação Profissional e Tecnológica SETEC/MEC. Tal concepção é significativa para a elaboração dos projetos políticos pedagógicos dos cursos técnicos a distância, permitindo reflexões acerca da formação de profissionais devidamente preparados para o mundo do trabalho e suas relações.

Rodrigues, Brod e Nascimento (2012, p. 42) destacam que, de acordo com o parecer do Conselho Nacional de Educação, os cursos técnicos a distância necessitam estar relacionados a quatro especificidades:

- Dispor de tutoria presencial e a distância, preconizando a importância de profissionais capacitados nos conteúdos dos componentes curriculares para auxiliar os estudantes em suas atividades individuais ou em grupo de forma presencial ou a distância através dos ambientes virtuais de aprendizagem;

- Oferecer material didático organizado, para facilitar a construção do conhecimento e para ser um mediador na interlocução entre os sujeitos do processo educacional;

- Proporcionar qualidade nos ambientes virtuais de aprendizagem pela tecnologia da comunicação e informação;

- Disponibilizar polos de apoio presencial para o desenvolvimento dos cursos e para servir de ponto de referência aos estudantes. 
Essas especificidades servem como base às instituições que desejam ofertar cursos na modalidade $\mathrm{EaD}$, evidenciando a importância e o cuidado que se deve ter na oferta dos cursos. A oferta de cursos técnicos a distância no CaVG segue essas orientações, pois se entende que tal modalidade ainda precisa ser problematizada a fim de permitir pesquisas que possam retratar e alavancar soluções efetivas na busca da qualidade da Educação Profissional e Tecnológica a distância.

Diante dessa realidade, foi necessário criar o Núcleo de Educação Técnica e Tecnológica Aberta e a Distância - NETTAD, órgão que assumiu a responsabilidade pela coordenação, supervisão e operacionalização dos cursos técnicos a distância, considerado um local de referência em educação a distância para a comunidade escolar. Sua gestão preconiza um desenho organizacional baseado em processos de trabalhos e na concepção colaborativa das equipes multidisciplinares (Nascimento, Moreira, Cancela e Sainz, 2011). Sua ação torna possível a implantação da Rede e-Tec Brasil no CaVG, uma vez que passa a ser o núcleo responsável pela produção de conteúdos e pela capacitação de professores pesquisadores, conteudistas e de professores tutores ${ }^{3}$.

Entretanto, para realizar o trabalho na modalidade a distancia foi necessário pensar em outra arquitetura pedagógica, para a qual há uma preocupação diferenciada na elaboração do componente curricular. Como os professores estavam, culturalmente, apropriados do ensino presencial, houve a necessidade de pensar a produção e organização do material e a estruturação das aulas considerando não apenas o conhecimento do conteúdo de cada disciplina, mas principalmente o conhecimento pedagógico presente em cada uma delas.

Para Shulman (1986) o entendimento do conteúdo implica olhar não apenas para os fatos ou conceitos de uma área; exige a compreensão das estruturas da disciplina que se ensina. $\mathrm{O}$ conhecimento do conteúdo recebe suporte do conhecimento pedagógico do conteúdo, avançando para formas de representação de ideias, analogias, ilustrações, exemplos, explicações e demonstrações que tornem o assunto compreensível a todos.

Este conjunto de conhecimentos permite ao professor estar situado no contexto em que desenvolve seu trabalho, bem como possibilita um movimento colaborativo entre diversos saberes, concretizando um corpo de "compreensões, conhecimentos, habilidades e disposições que são necessários para que o professor possa propiciar processos de ensinar e de aprender, em diferentes áreas de conhecimento, níveis, contextos e modalidades de ensino" (Mizukami, 2004, p. 38). 
Buscando dar significado às ideias propostas por Shulman, cada disciplina foi organizada a partir de um fluxograma (Figura 1).

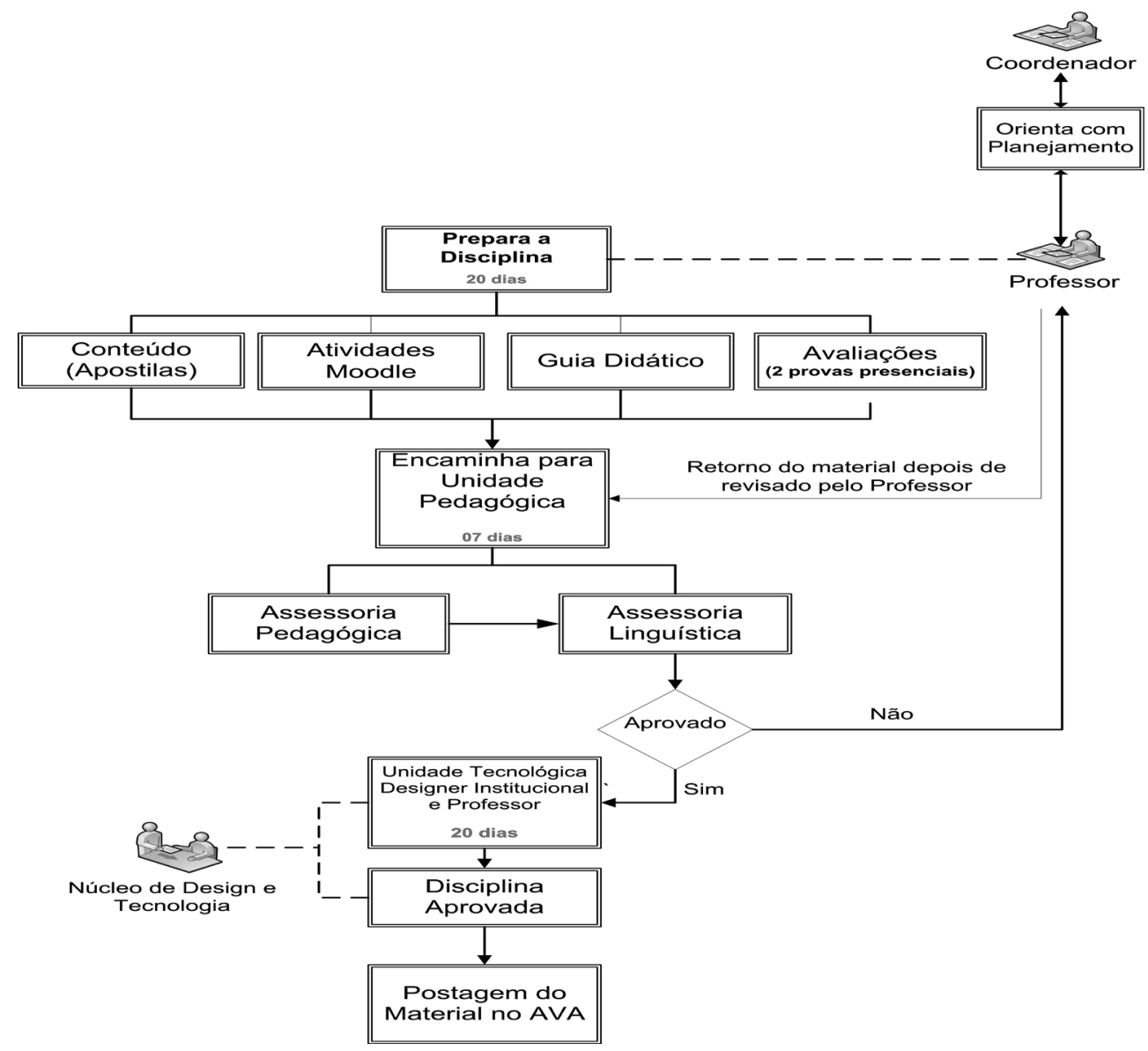

Figura 1. Produção de Material Didático

Fonte: Nascimento et al., 2011, p.10.

A preparação das disciplinas é de responsabilidade do professor que, junto com o coordenador do curso, realiza o seu planejamento. Posteriormente, a produção dos conteúdos recebe uma orientação pedagógica a fim de permitir uma compreensão do assunto. Na sequência, o conteúdo passa por uma revisão linguística valorizando o processo dialógico necessário à EaD. Após a aprovação dessas etapas, a disciplina passa à diagramação e posterior postagem no ambiente virtual de aprendizagem. É importante salientar que, além de sinalizar para a importância da revisão e controle de prazos, o fluxograma proporciona a reflexão, a colaboração e o compartilhamento entre os diversos saberes. 
Os primeiros anos do NETTAD podem ser identificados como um período em que o aprender e o ensinar foi marcado por um emocionar configurado na convivência com o outro e entrelaçado num linguajear próprio daquela rede de conversação. Maturanae Verden-Zöller (2004a, p.9) dizem-nos que "ao viver fluímos de um domínio de ações a outro, num contínuo emocionar (vivenciar as emoções) que se entrelaça com nosso linguajear. A esse entrelaçamento chamamos de conversar". É nesse viver que foi possível superar as dificuldades e dar continuidade e sustentabilidade às ações de $\mathrm{EaD}$.

Em 2010, o CaVG abriu novo processo seletivo ofertando mais dois novos cursos (Administração e Contabilidade), totalizando quatro cursos técnicos num total de 1250 vagas em 10 polos municipais. Em 2012, foram ofertadas 2350 vagas em 17 polos municipais e, no ano seguinte, através do Edital 154/2013 do IFSul- que dispõe sobre processo seletivo para ingresso nos cursos da modalidade de Educação a Distância oferecido pelo sistema Rede e-Tec Brasil no campus CaVG -,foram ofertadas 2800 vagas em 20 polos municipais.

Atualmente, na estrutura organizacional do campus, a oferta dos cursos técnicos a distancia do CaVG, está sob a gestão do Departamento de Educação a Distância DEAD, subordinado a Direção de Ensino do Campus ${ }^{4}$.

A partir dessa experiência, o Campus Pelotas Visconde da Graça sofre uma aculturação, por conta do uso de novas tecnologias, da presença de novos atores e adoção de novas práticas pedagógicas. Para Maturana (2004b) o surgimento de uma nova cultura ocorre de forma sistêmica, sendo que a rede de conversações na qual a comunidade está inserida se modifica a partir de uma nova configuração do emocionar humano. Com isso, é possível pensar que EaD está inserida numa rede específica de conversações, sustentada no emocionar dos membros que dela participam. São professores, alunos, professores tutores, programadores, pedagogos, webdesigners, administradores, envolvidos com o compromisso de ofertar uma educação a distância profissional e tecnológica que venha ao encontro das demandas sociais. Ainda, segundo o autor, a mudança cultural é a alteração na configuração do atuar e do emocionar dos membros da rede fechada de conversações; o emocionar representa as ações e comportamentos, enquanto que o linguajear significa o modo de conviver.

Nessa epistemologia, é possível afirmar que a instituição CaVG estabelece uma nova cultura por conta das particularidades estabelecidas pelo fenômeno da educação a distância, ou seja, são novas ações e comportamentos que se configuram num grupo específico, o qual se propõe e está disposto a vivenciar novas experiências, 
enquanto sujeitos ativos e atuantes, seja na docência, na gestão ou em outras áreas do conhecimento.

\section{A ESTRATÉGIA METODOLÓGICA DO ESTUDO}

A abordagem epistemológica em torno do desenvolvimento das ciências emerge de estudos, discussões, contraposições de diversos cientistas, filósofos e educadores que se propõem a refletir sobre a natureza do conhecimento científico.

Ao definirem o conhecimento científico, Lakatos e Marconi (1991) afirmam que constitui um conhecimento contingente, pois sendo suas afirmações verdadeiras ou falsas são concebidas através da experiência; é sistemático, por ser ordenado em um sistema de ideias; é verificável devendo haver a comprovação das afirmações; é falível, por não ser definitivo. Para Maturana (1997a, p. 125) “a ciência, é necessariamente um domínio de afirmações operacionais socialmente aceitas, validadas por um procedimento que especifica o observador que as gera como observador padrão [...]”.

O problema de pesquisa para Martins (2002, p.20) “pode surgir de circunstâncias pessoais ou profissionais, da experiência científica própria ou alheia, da sugestão de uma personalidade superior, do estudo, da leitura de grandes obras, da leitura de revistas especializadas, etc.”. Por sua vez, Gil (1996) afirma que o problema pode vir de qualquer questão que não obteve solução, trazendo discussão em qualquer domínio do conhecimento.

Em nosso olhar para a ciência, vemos um campo complexo de amplo debate com capacidade de gerar perturbações significativas, permitindo reflexões em torno das relações existentes entre razão, emoção e cotidiano (Maturana, 1997b).

O presente estudo apresenta resultados de uma pesquisa envolvendo a Educação Profissional e Tecnológica a distancia no IFSul/CaVG e tem como foco as professoras que atuam como coordenadoras de dezessete polos de apoio presencial. A escolha das coordenadoras, para um primeiro estudo do campo de pesquisa, é decorrente da posição que ocupam como educadoras, gestoras de polos, coordenando a parte administrativa (estrutura física e de pessoal) e auxiliando na mobilização, motivação e nas demais relações didático-pedagógicas junto aos estudantes.

Para conhecer como a experiência na Educação Profissional e Tecnológica a distancia do IFSul/CaVG tem sido recebida nos polos de apoio presencial, solicitamos que cada coordenadora respondesse, por email, a duas questões sobre a estrutura da Rede e-Tec Brasil e sobre como os cursos técnicos promovem e/ou colaboram para o desenvolvimento econômico e social da região. 
A partir do retorno de nove coordenadoras, optamos, para análise das questões, pela metodologia do Discurso do Sujeito Coletivo (DSC), que permitiu conhecer o discurso desta coletividade, na voz das coordenadoras. De acordo com Lefèvre e Lefèvre (2012, p. 17) o DSC é

[...] o desdobramento natural do seguinte raciocínio lógico: se, em qualquer sociedade (como todos sabem), os indivíduos compartilham ideias, opiniões, crenças ou representações, a expressão dessas opiniões compartilhadas poderia comportar a reunião em discursos-síntese dos conteúdos e argumentos que conformam essas opiniões semelhantes.

A proposta do DSC consiste em analisar diferentes opiniões de forma a extrair expressões-chaves semelhantes para compor um discurso único na primeira pessoa do singular visando "dar luz ao conjunto de individualidades semânticas componentes do imaginário social” (Lefèvre e Lefèvre, 2005, p.16).

Analisando as respostas das coordenadoras de polo, foi possível encontrar uma recursividade no conversar que fez emergir os discursos coletivos: "A democratização do ensino profissional" (DSC-1) e "A formação profissional de nível técnico" (DSC2), que a seguir serão discutidos e analisados teoricamente.

\section{PROBLEMATIZANDO OS DISCURSOS COLETIVOS}

Para compreendermos como a Rede e-Tec Brasil é percebida nos polos de apoio presencial do IFSul- Campus Pelotas Visconde da Graça, analisamos os discursos coletivos das coordenadoras de nove polos. Da análise emergiu um primeiro discurso (DSC-1), denominado "A democratização do ensino profissional" e apresentado a seguir.

A Rede e-Tec Brasil é de extrema relevância para as comunidades que
estão distantes dos grandes centros acadêmicos, pois está oportunizando
aos jovens e adultos que não tem disponibilidade de tempo para estudarem
em turmas regulares o retorno a escola. Traz oportunidades de trabalho e
de vida para pessoas que não teriam outra forma de ter acesso ao ensino
técnico. Forma vários profissionais e nas mais diversas áreas, o que faz
uma grande diferença, uma vez que muitas pessoas não possuiriam outra
forma de acesso aos estudos se não essa em EaD. A grande maioria ao
concluir o curso técnico já está buscando a continuidade através de cursos
superiores. Por isso, promove a inclusão e a democratização do Ensino.

DSC- 1. A democratização do ensino profissional 
O discurso expressa a representatividade que a Rede e-Tec Brasil possui nos municípios polos. Isso nos reporta ao entendimento de que a educação no seu modelo tradicional não atende as inúmeras demandas educacionais da sociedade moderna, necessitando viabilizar mecanismos que possam garantir o atendimento dessas novas demandas, sejam elas de educação básica, profissional ou superior.

A educação a distância “[...] tende doravante a se tornar cada vez mais um elemento regular dos sistemas educativos necessário não apenas para atender a demanda e/ou a grupos específicos, mas assumindo funções de crescente importância, especialmente no ensino pós-secundário[...]" (Belloni, 2008, p.4). Ainda, segundo a autora, a EaD sinaliza como meio possível de superar os problemas educacionais emergenciais, sendo possível atender as crescentes demandas por educação e que as mudanças ocorridas no acesso à informação e cultura estão cada vez mais midiatizadas, bem como os processos de produção e de trabalho que reivindicam transformações nos sistema educacionais. A educação a distância reporta-nos a uma nova maneira de ensinar e aprender.

\section{Para Moore e Kearsley (2008, p.21) com a EaD}

[...] mais pessoas estão obtendo acesso mais facilmente a mais e melhores recursos de aprendizado do que podiam no passado, [...]. À medida que a utilização da educação a distancia se disseminar, populações anteriormente em desvantagem, como os alunos de áreas rurais ou de regiões no interior das cidades, poderão fazer cursos nas mesmas instituições e com o mesmo docente que anteriormente estavam disponíveis apenas para alunos em áreas privilegiadas [...].

O fragmento do discurso coletivo "Traz oportunidades de trabalho e de vida para pessoas que não teriam outra forma de ter acesso ao ensino técnico" indica a clara aceitação da modalidade de educação a distância como promotora e viabilizadora de mudanças na vida daqueles que não possuem acesso aos "bancos escolares" regulares.

A EaD surge como oportunidade e rompe com as limitações de espaço e tempo e, através dos ambientes virtuais, permite erigir o conhecimento formando sujeitos capazes de dar conta da complexidade da sociedade contemporânea. Também é percebida como uma modalidade capaz de modificar o contexto educacional, promovendo interatividade, autonomia e colaboração.

É possível sinalizar de forma positiva que a educação a distância pode ser transformadora à medida que possibilita o acesso da população à educação, no fragmento do discurso coletivo "forma vários profissionais e nas mais diversas áreas, 
o que faz uma grande diferença, uma vez que muitas pessoas não possuiriam outra forma de acesso aos estudos se não essa”.

Por outro lado, consideramos que a modalidade de educação a distância vai além da premissa de possibilitar o acesso àqueles que se encontram distanciados social e geograficamente dos tradicionais sistemas de ensino. Ela possibilita um engendramento para uma nova concepção de ensinar e de aprender atendendo uma demanda de saberes e um novo perfil de estudante. Isso corrobora o entendimento de que a educação a distância traz a quebra do paradigma educacional tradicional, realizando um movimento da concepção "de educação como sistema fechado, voltado para a transmissão e transferência, para um sistema aberto, implicando processos transformadores que decorrem da experiência de cada um dos sujeitos da ação educativa" (Forgrad, 2001, p.14 apud Almeida, 2002, p.3).

Para Maturana (1999) a educação a distância, quando aceita e acolhida por todos, possibilita uma modificação no ouvir, ver e fazer na convivência de um país, pois permite a cooperação e a valorização do indivíduo derrubando as barreiras culturais e econômicas. Ainda segundo o autor (p.149, tradução nossa) a EaD “permite ampliar a realização do viver democrático", criando um espaço reflexivo onde o linguagear e o emocionar são comuns, possibilitando o desaparecimento das diferenças culturais a que somos submetidos.

O discurso coletivo destaca ainda que a Rede e-Tec Brasil como democratizadora e promotora de oportunidades de trabalho corrobora a necessidade de formular políticas de educação profissional que atendam as necessidades daqueles que vivem do trabalho, o que pode ser observado na Lei que institui o Pronatec, envolvendo um conjunto de iniciativas tais como: Programa Brasil Profissionalizado, Rede e-Tec Brasil, Bolsa-formação, etc. Todas essas ações convergem para a ampliação da oferta de cursos de Educação Profissional e Tecnológica.

No entanto, ainda que medidas sejam realizadas para fomentar o acesso à Educação Profissional e Tecnológica, precisamos ir além da sua implantação. Pensamos que elas devam emanar da sociedade e serem consolidadas por ela, de forma que as ações educativas estejam pautadas num projeto de Estado e dentro de uma concepção social. Nessa perspectiva, é possível que as instituições de ensino validem essas ações, bem como sua continuidade através da elaboração de projetos político-pedagógicos que venham ao encontro das necessidades da sociedade a fim de que uma nova cultura se configure no fundamento emocional dessa rede de conversação. Para Maturana (2006c, p. 129) emoções "são disposições corporais dinâmicas que especificam os domínios de ações nos quais os animais, em geral, 
e nós seres humanos, em particular, operamos num instante". São as emoções que determinam nossas ações.

Em uma unicidade de desejos e emoções, vamos ao encontro do segundo discurso coletivo (DSC-2), que tece considerações acerca da oferta dos cursos técnicos do IFSul- Campus Pelotas Visconde da Graça, o qual denominamos "A formação profissional de nível técnico".

A oferta de Ensino Profissional de nível médio promove a formação de
Técnicos para atender a demanda e consequentemente possibilitando a
geração de mecanismos para impulsionar o desenvolvimento econômico e
social. A qualificação dos profissionais faz com que eles busquem e consigam
oportunidades melhores de trabalho ou mesmo que venham a crescer
dentro das empresas em que já estão trabalhando. Acredito que a formação
seja adequada para a inserção ao mercado de trabalho. Os cursos técnicos
do CAVG são voltados para atividades que predominam ou necessitam se
desenvolver na região sul possibilitam novas oportunidades de trabalho;
preparando novos empreendedores e qualificando serviços. A melhoria de
trabalho reflete em melhores condições de vida para si e seus familiares
possibilitaram à população um novo horizonte, visando uma educação de
qualidade. Atingem diferentes áreas do conhecimento, tem uma boa grade
curricular, com disciplinas bem organizadas e conteúdos atualizados, que
estão de acordo com as necessidades do mercado. Sentimos a falta de aulas
práticas mais frequentes, os alunos desistiriam em menor número, pois as
aulas práticas motivam imensamente aos alunos.

DSC2. A formação profissional de nível técnico

No discurso coletivo, as coordenadoras de polo destacam que "A oferta de Ensino Profissional de nível médio promove a formação de Técnicos para atender a demanda e consequentemente possibilitando a geração de mecanismos para impulsionar o desenvolvimento econômico e social". O coletivo expressa a importância do ensino profissional e tecnológico no desenvolvimento econômico e social, vindo ao encontro do entendimento dos Institutos Federais, que estão comprometidos em promover o desenvolvimento regional, através da formação de técnicos e tecnólogos, oferecendo à sociedade profissionais com formação valorizada e necessária em seu contexto local e regional.

Na nascente dos Institutos, está o desejo de formar, não apenas um profissional, mas um cidadão. As palavras de Pacheco (2010, p.7) indicam a filosofia dos institutos e o compromisso assumido com as comunidades para as quais ofertam cursos de formação, pois o "objetivo central não é formar um profissional para o mercado, mas sim um cidadão para o mundo do trabalho, o qual poderia ser tanto técnico, como 
um filósofo, um escritor ou tudo isto. Significa superar o preconceito de classe de que um trabalhador não pode ser um intelectual, um artista".

Tal afirmação é corroborada no discurso coletivo das coordenadoras: "A qualificação dos profissionais faz com que eles busquem e consigam oportunidades melhores de trabalho ou mesmo que venham a crescer dentro das empresas em que já estão trabalhando".

O discurso mostra o entendimento e a vontade das comunidades locais em receber cursos que promovam oportunidades de trabalho; com componentes curriculares que possibilitem a qualificação dos profissionais para geração de emprego e renda, evidenciando a necessidade de desenvolvimento desses municípios, carentes de mão de obra qualificada e/ou de melhorias nos postos de trabalho.

Os cursos técnicos do CaVG são voltados para atividades que predominam ou necessitam se desenvolver na região sul possibilitam novas oportunidades de trabalho; preparando novos empreendedores e qualificando serviços. (DSC-2).

A importância do contexto regional na formação dos egressos encontra respaldo na compreensão de que os cursos devem buscar atender os arranjos produtivos locais como forma de desenvolvimento econômico e social e de permanência dos jovens em seus locais de origem, indo ao encontro da filosofia dos Institutos Federais de Educação, Ciência e Tecnologia, que trazem em seu artigo $6^{a}$ inciso I e II, entre suas finalidades e características, a oferta da educação profissional e tecnológica com ênfase no desenvolvimento local, regional e nacional, atendendo as demandas sociais e peculiaridades regionais.

Um último aspecto a ser observado no discurso, pois é um balizador de ações futuras dos institutos que pretendem oferecer Educação Profissional e Tecnológica, na modalidade a distância, diz respeito ao desenvolvimento pleno dos cursos envolvendo tanto a parte teórica quanto a prática. As coordenadoras de polo destacam que sentem "falta de aulas práticas mais frequentes, os alunos desistiriam em menor número, pois as aulas práticas motivam imensamente aos alunos”. Suas falas refletem uma das tantas dificuldades que são encontradas na implantação de cursos técnicos a distância, evidenciando a necessidade de soluções efetivas nesse sentido.

Nessa discussão foi proposta pela Rede e-tec Brasil a criação de laboratórios móveis montados em caminhões, atendendo as especificidades de cada curso, o que permitiria o deslocamento para os polos, sanando a problemática da ida dos alunos 
às instituições de ensino ou às indústrias relacionadas com as áreas do conhecimento de cada curso. É importante salientar ainda que o aumento da carga horária referente às aulas práticas não é garantia de redução da evasão, pois são vários os elementos que constituem essa problemática. No entanto, essa referência de motivação através das aulas práticas torna-se um importante elemento de reflexão para a revisão dos projetos pedagógicos de cursos.

\section{CONSIDERAÇÕES FINAIS}

Os discursos demonstram a demanda e aceitação dos cursos técnicos a distância do IFSul/CaVG, identificando a necessidade de formação profissional para a melhoria das condições de emprego e renda, bem como o entendimento de que parte do desenvolvimento econômico e social dos municípios passa pela oferta da Educação Profissional e Tecnológica.

A profissionalização está relacionada a um cenário de possibilidades efetivas, na qual os programas nacionais de educação de fato venham a configurar um projeto político-pedagógico democrático capaz de atender as especificidades dos arranjos produtivos locais, o acesso aos sistemas de ensino e a valorização dos professores e de todos os demais que trabalham com a educação.

A criação da Rede e-Tec Brasil é uma ação do governo federal que dá amplas possibilidades para a expansão do ensino técnico e tecnológico a distância no país. Sua consolidação, ainda que possa representar uma política pública capaz de sanara deficiência da oferta do ensino profissional, depende de compromisso e continuidade e não apenas de uma disponibilidade de orçamento financeiro. O estudo mostrou que as políticas governamentais necessitam estar articuladas e comprometidas com o desenvolvimento social, para que a sua ação seja capaz de provocar transformações significativas no indivíduo e na sociedade.

A modalidade de educação a distância permite a democratização e inclusão do ensino, no entanto, para efetivação dessa condição, é preciso ir além da análise quantitativa da oferta de vagas. Somente a expansão de vagas não é garantia da qualidade da formação do egresso tampouco atende os objetivos de formar não apenas um técnico, mas sim um cidadão emancipado e apto a tomar decisões no mundo do trabalho.

A institucionalização da Rede e-Tec passa pela discussão da necessidade de buscar um espaço próprio capaz de situar suas especificidades, bem como sinalizar com uma legislação exclusiva para esse nível e modalidade de ensino, uma vez que 
modifica a mediação pedagógica nos processos de ensinar e aprender exige um novo desenho organizacional da gestão escolar e demanda o uso intenso das tecnologias de comunicação e informação.

Para finalizar, destacamos que, apesar do entendimento e sinalização para o uso massivo do computador e da internet, é preciso considerar que ainda existe uma parte significativa da população brasileira que não aufere desses recursos tecnológicos, o que mostra a importância da constituição dos polos de apoio presencial enquanto unidades operacionais responsáveis pelo desenvolvimento descentralizado de atividades pedagógicas e administrativas, bem como enquanto interlocutores dos diversos sujeitos que participam do desenvolvimento da Educação Profissional e Tecnológica a distância.

\section{NOTAS}

1. Programa Nacional de Acesso ao Ensino Técnico e Emprego (Pronatec) foi criado pelo Governo Federal, em 2011, com o objetivo de ampliar a oferta de cursos de educação profissional e tecnológica em todas as modalidades de ensino.

2. Site $<$ http://redeetec.mec.gov.br/ $>$

3. As capacitações ocorrem através de Seminários anuais objetivando a discussão, a reflexão e a realização de encaminhamentos na busca de melhorias na efetivação dos cursos técnicos a distancia.

4. Regimento Interno do Campus Pelotas Visconde da Graça - IFSUL.

\section{REFERÊNCIAS BIBLIOGRÁFICAS}

Almeida, M. E. B. Educação à distância no Brasil: diretrizes políticas, fundamentos $e$ práticas. Belo Horizonte, MG [em línea] Disponível em http://www.ich. pucminas.br/pged/interact/viewfile. php/1/file/17/51/PDF.pdf (consulta 2013, 10 de março).

Antunes, J. L. (1996). CAVG - História de um patronato. Pelotas, RS: UFPEL.

Brasil. (2005). Presidência da Republica. Decreto 5.622. Brasília: Casa Civil [em línea] Disponível em: http://www. planalto.gov.br/ccivil 03/Ato20042006/2005/decreto/D5622.htm (consulta 2013, 10 de março).
Brasil. (2007). Presidência da Republica. Decreto 6.301. Brasília: Casa Civil [em línea] Disponível em: http://www. planalto.gov.br/ccivil 03/ Ato2007010/2007/Decreto/D6301impressao. htm (consulta 2013, 10 de março).

Brasil. (2009). Ministério da Educação. Centenário da Rede Federal de Educação Profissional e Tecnológica. [em línea] Disponível em: http://portal. mec.gov.br/setec/arquivos/centenario/ historico educacao profissional.pdf (consulta 2013, o5 de abril).

Brasil. (2011). Presidência da Republica. Decreto 7.589. Brasília: Casa Civil. [em 
línea] Disponível em: http://www. planalto.gov.br/ccivil 03/ Ato20112014/2011/Decreto/D7589.htm (consulta 2013, 16 de abril).

Brasil. (2012). Ministério da Educação. Parecer CNE/CEB $n$ 11. [em línea] Disponível em: http://portal.mec. gov.br/index.php?option $=$ com content\&id $=17576 \&$ Itemid $=866$ (consulta 2013, 16 de abril).

Belloni, M. L. (2008). Educação a Distância. Campinas, SP: Autores Associados.

Castells, M. (2002). Sociedade em Rede. São Paulo: Paz e Terra.

Capra, F. (1989). O ponto de Mutação. São Paulo: Pensamento-Cultrix.

Gil, A. C. (1996). Como Elaborar Projetos de Pesquisa. São Paulo: Atlas.

IFSUL. Regimento Interno Campus Pelotas Visconde da Graça.[em línea] Disponível em: $\quad$ http://www.ifsul.edu.br/index. php?option $=$ com docman \&Itemid $=38$ (consulta 2013, 02 de maio).

Lakatos, E. M.; Marconi, M. A. (1991). Fundamentos de Metodologia Científica. São Paulo: Atlas.

Lefevre, F.; Lefevre, A. M. (2012). Pesquisa de Representação Social - um enfoque qualitativo. Brasília, DF: Liber Livro Editora.

Lefevre, F.; Lefeure, A. M. (2005). O Discurso do Sujeito Coletivo - Um novo enfoque em pesquisa qualitativa (Desdobramentos). Caxias do Sul, RS: Educs.

Martins, G. A. (2002). Manual para elaboração de monografia $e$ dissertações. São Paulo: Atlas.

Mattar, João. (2012). Tutoria e Interação em Educação a Distância. São Paulo: Cengage Learning.

Maturana, H. R. (1997). A Ontologia da Realidade. Belo Horizonte: UFMG.

Maturana, H. R. (1999). Transformación En la convivência. Santiago: Dolmen.
Maturana, H. R.; Zoller, G. V. (2004). Amar e Brincar - Fundamentos esquecidos do Humano. São Paulo: Palas Athena.

Maturana, H. R. (2006). Cognição, Ciência e Vida Cotidiana. Belo Horizonte: UFMG.

Mizukami, M. G. N. (2004). Aprendizagem da docência: algumas contribuições de L. S. Shulman. Revista Educação, 2 (29), (3349). [em línea] Disponível em: HTTP:// www.ufsm.br/ce/revista (consulta 2013, O2 Junho).

Moore, M.; Kearsley, G. (2008). Educação a Distância - uma visão integrada. São Paulo: Cengage Learning.

Nascimento, C. O.; Moreira, I. G.; Cancela, M. P. N.; Sainz, R. L. (2011). O Desenho Organizacional da EaD: a experiência no âmbito do NETTAD. Anais. UFMG. Ouro Preto. VIII Congresso Brasileiro de Ensino Superior a Distância.

Silva, C. J. R. (2009). Institutos Federais lei 11.892, de 29/11/2008: comentários e reflexões. Natal: IFRN. [em línea] Disponível em: http://portal.mec.gov. br/index.php?option $=$ com content\& view $=$ article $\&$ id $=12503 \&$ Itemid $=841$ (consulta 2013, 14 de Maio).

Shulman, L. S. (1986). Those Who Understand: Knowledge Growth in Teaching. Educational Researcher, 2 (15), (4-14). [em línea] Disponível em: http://links.jstor.org/sici?sici=0013189X\%28198602\%2915\%3A2\%3C4\%3A TWUKGI\%3E2.0.CO\%3B2-X (consulta 2013, 02 de Junho).

Pacheco, E. M.; Pereira, L. A. C.; Sobrinho, M. D. (2010). Institutos Federais de Educação, Ciência e Tecnologia: Limites e Possibilidades. Linhas Críticas, 30 (16), (71-88). [em línea] Disponível em: http://seer.bce.unb.br/index.php/ linhascriticas/article/view/1429/1065 (consulta 2013, 10 de março).

Pacheco, E. M. (2010). Os Institutos Federais - Uma Revolução na Educação Profissionale Tecnológica. Brasília: MEC [em línea] Disponível em: http://portal. 
mec.gov.br/index.php?option=com co ntent\&view $=$ article\&id $=12503 \&$ Item $\mathrm{id}=841$ (consulta 2013, 05 de março).

Rodrigues, S. C.; Brod, F. A.; Nascimento, C. O. (2013). A Mediação Pedagógica na Educação Profissional a Distância, Ribeiro e Henning, Diálogos na Educação em Ciências. Rio Grande: Editora da FURG, (41-50).

\section{PERFIL ACADÉMICO Y PROFESIONAL DE LAS AUTORAS}

Cinara Ourique do Nascimento. Doutoranda em Educação e Ciências: Química da Vida e Saúde pela Universidade Federal do Rio Grande (FURG). Mestre em Administração pela UFSM (2005). Especialista em Gestão Estratégica Empresarial pela UFSM (2003). Graduada em Ciências Econômicas pela UFSM (1997). Professora Assistente do Instituto Federal de Educação, Ciência e Tecnologia - IFSul - Campus Pelotas Visconde da Graça - CaVG. É membro do Grupo de Pesquisa Educação a Distância e Tecnologias - FURG.

E-mail: cinaraourique@gmail.com

Sheyla Costa Rodrigues. Pedagoga com Mestrado em Educação pela Pontifícia Universidade Católica do Rio Grande do Sul. Doutorado em Informática na Educação pela Universidade Federal do Rio Grande do Sul. Professora na Universidade Federal do Rio Grande - FURG. Desenvolve e orienta projetos de pesquisa em Educação: ênfase em Formação de Professores, Educação a Distância e Tecnologias Digitais. Coordenadora Adjunta do Programa de Pós-Graduação em Educação em Ciências: Química da Vida e Saúde.

E-mail: sheylacrodrigues@gmail.com

\section{DIRECCIÓN POSTAL DE LAS AUTORAS}

Instituto Federal de Educação, Ciência e Tecnologia - IFSul Campus Pelotas Visconde da Graça - CaVG. Av. Ildefonso Simões Lopes, 2791 - Bairro Arco-Iris 96060-290 - Pelotas, RS - Brasil

Universidade Federal do Rio Grande - FURG Programa de Pós-Graduação em Educação em Ciências: Química da Vida e Saúde Avenida Itália Km 8 - Campus Carreiros 96203-900 - Rio Grande, RS - Brasil 
Fechas de recepción del artículo: 02/12/13

Fecha de aceptación del artículo: 30/04/14

\section{Como citar este artículo:}

Ourique do Nascimento, C.; Costa Rodrigues, S. (2014). A educação a distância como oportunidade de formação profissional e tecnológica. RIED. Revista Iberoamericana de Educación a Distancia, volumen 17, $\mathrm{n}^{0}$ 2, pp. 151-171. 